\title{
ANALYSIS OF NON-UNIFORM SHRINKAGE EFFECT IN BOX GIRDER SECTIONS FOR LONG-SPAN CONTINUOUS RIGID FRAME BRIDGE
}

\author{
Zhuoya YUAN ${ }^{1}$, Pui-Lam NG² ${ }^{2}$ Darius BAČINSKAS ${ }^{3}$, Jinsheng DU ${ }^{4^{*}}$ \\ ${ }^{1}$ School of Highway, Chang'an University, Nanier Huan Road, Xian, China \\ ${ }^{2}$ Institute of Building and Bridge Structures, Vilnius Gediminas Technical University, Vilnius, Lithuania \\ ${ }^{3}$ Dept of Reinforced Concrete Structures and Geotechnics, Vilnius Gediminas Technical University, Vilnius, Lithuania \\ ${ }^{4}$ School of Civil Engineering, Beijing Jiaotong University, Beijing, China
}

Received 09 August 2017; accepted 02 November 2017

\begin{abstract}
To consider the effect of non-uniform shrinkage of box girder sections on the long-term deformations of continuous rigid frame bridges, and to improve the prediction accuracy of analysis in the design phase, this paper proposes a new simulation technique for use with general-purpose finite element program. The non-uniform shrinkage effect of the box girder is transformed to an equivalent temperature gradient and then applied as external load onto the beam elements in the finite element analysis. Comparative analysis of the difference in deflections between uniform shrinkage and nonuniform shrinkage of the main girder was made for a vehicular bridge in reality using the proposed technique. The results indicate that the maximum deflection of box girder under the action of non-uniform shrinkage is much greater than that under the action of uniform shrinkage. The maximum downward deflection of the bridge girder caused by uniform shrinkage is $5.6 \mathrm{~mm}$ at 20 years after completion of bridge deck construction, whereas the maximum downward deflection caused by non-uniform shrinkage is $21.6 \mathrm{~mm}$, which is 3.8 times larger. This study shows that the non-uniform shrinkage effect of the girder sections has a significant impact on the long-term deflection of continuous rigid frame bridge, and it can be accurately simulated by the proposed transformation technique.
\end{abstract}

Keywords: continuous rigid frame bridge, equivalent temperature gradient, long-term deformation, non-uniform shrinkage effect.

\section{Introduction}

In designing long-span prestressed concrete bridges, excessive long-term downward deflection has been a concern among structural engineers. Compared to simply supported bridge spans, continuous bridge spans can eliminate the movement joints, so as to provide a smooth riding surface and ease the maintenance. Therefore, continuous rigid frame bridge is an attractive structural option. From vast experience, the deflection of a prestressed continuous rigid frame bridge deck at circa 500 days after completion of construction would amount to $70 \%$ to $90 \%$ of the ultimate values, and after that, the deflection would increase at a much lower rate and eventually levels off (Robertson, 2005). However, there had been observations in reality that the actual long-term deflections were significantly larger than the predicted values, and even many years after completion of bridge construction, the deflections showed no sign of convergence but continued to increase steadily (Kř́stek, Bažant, Zich, \& Kohoutková, 2005, 2006; Xu, Tan, \& Li, 2010). Therefore, it is necessary to investigate the underlying causes of the excessive longterm deflections, and, given the common usage of Finite Element Method (FEM) in structural design, to devise a reliable method for assessing such in the finite element (FE) analysis for practical adoption.

In general, the deflection of prestressed concrete bridge girders is a complex nonlinear behaviour influenced by the long-term prestress loss, concrete shrinkage and creep characteristics, cracking of the bridge girder, construction tolerances, and the interactions among these factors $(\mathrm{Xu}$, Zhang, \& Xu, 2007). This is in line with the analytical results based on the FEM, which is commonly used for structural analysis and design by both engineers and researchers. For instance, Takács (2002) analysed the longterm deflections of bridge decks based on three real bridges in Norway. By taking into account the time-dependent effects including shrinkage and creep as well as prestress

${ }^{*}$ Corresponding author. E-mail: jshdu@bjtu.edu.cn 
loss, the predicted deflections agreed reasonably well with the observed values. The studies by Kř́stek, Bažant, Zich, and Kohoutková (2006) and Křístek, Vráblík, Bažant, Li, and $\mathrm{Yu}$ (2009) revealed the sensitivity of non-uniform shrinkage on the deformational behaviour of box girder bridges. Due to differences in the thickness of and the environmental conditions faced by the top and bottom slabs, the slabs would exhibit different rates of shrinkage, which would play an important role in affecting the curvature and the deflection. All in all, the non-uniform shrinkage effect has great influence on the long-term deformations of bridge girders.

On the basis of the nonlinear diffusion theory (Bažant \& Najjar, 1972) that models the nonlinear water diffusion in unsaturated concrete, Bažant, Yu, \& Li (2012a, 2012b) established the physical model of a collapsed long-span bridge in Palau as part of the forensic investigation. In the model, the variation of exposure conditions of each member to the ambient environment was taken into account, such that each solid element is characterized by a distinct drying rate. The shrinkage behaviour of the physical components is described by the B3 Model for deformational analysis (Bažant \& Baweja, 2000) to simulate the actual state of time-dependent dimensional change. It should, nevertheless, be noted that the collapse was attributed to a number of design flaws, construction quality, and workmanship factors, including an inadequate allowance of creep deflection (Bažant et al., 2011; Bažant, Hubler, \& Yu, 2011). The nonlinear diffusion theory was also applied by Huang (2010) in developing a computation method for thin-walled box girder to consider the non-uniform shrinkage effect, so as to improve the accuracy of long-term deflection analysis.

By means of FE analysis using plate elements, Xiang, Tan, $\mathrm{Xu}$, and Yan (2011) analysed the long-term deformations of a concrete box girder bridge taking into account the effects of non-uniform shrinkage. From their study, it was concluded that the non-uniform shrinkage augmented the deflection of cantilever beam by approximately $30 \%$, and ultimately, the deflection of continuous rigid frame bridge span converges to a certain increased value under the combined effects of creep and shrinkage. Zhang, Meng, and Liu (2011) derived the equivalent shrinkage strain formulas based on plane section assumption and simulated the equivalent shrinkage strain with prescribed contraction of structural components. By employing this methodology, they assessed the long-term deformations of Sutong Bridge in China with the inclusion of nonuniform shrinkage. Navrátil and Zich (2013) analysed the long-term deflections of a post-tensioned segmentally erected bridge across Vltava River in the Czech Republic using the FEM and compared the analytical results with the field measurement data (Zich, 2002; Zich \& Navrátil, 2011), and they conducted parametric analysis for various cross-section dimensions, environmental conditions, and shrinkage model coefficients. The above studies pointed out the remarkable effect of non-uniform shrinkage in increasing the long-term deflections of rigid frame bridges.
The omission of non-uniform shrinkage in the design process would lead to underestimation of the deflections.

Though vast research had been devoted to investigate the time-dependent effects on deflection of continuous rigid frame bridge due to concrete shrinkage and creep, the effect of non-uniform shrinkage of box girder section had rarely been studied. In design practice, the non-uniform shrinkage effect is often neglected due to the absence of guidance in design codes and lack of well-established methodology to cater for such effect. Given the significance of non-uniform shrinkage in determining the longterm deflections of a bridge girder, as will be shown in this paper, the authors hereby propose a new simulation technique that can be applied to common general-purpose FE program. The non-uniform shrinkage effect of the box girder is transformed to an equivalent temperature gradient and then applied as external load onto the beam elements in the FE analysis. The proposed simulation technique is simple and can be readily adopted in the practice of concrete bridge design. To illustrate the technique, a long-span prestressed concrete continuous rigid frame vehicular bridge in real life is selected for analysing its longterm deflections under the scenarios of uniform shrinkage and non-uniform shrinkage. Comparison of the numerical results reveals the significant impact of non-uniform shrinkage on the long-term deflection behaviour.

\section{Shrinkage of bridge deck}

In conducting structural analysis of bridges, the shrinkage effect of the bridge deck is usually represented by the shortening movement in the longitudinal direction of the bridge. For given environmental conditions, given age and material properties of concrete, such movement is solely dependent on the effective thickness of the structural component. At this juncture, the effective thickness is evaluated as two times the concrete sectional area divided by the perimeter exposed to ambient as per British Standard BS 5400 (British Standards Institution, 1990) and CEB-FIP Model Code 1990 (Comité Euro-International du Béton, 1993). Therefore, the uniform dimensional change over the bridge girder cross-section is characterized by a shrinkage strain, which is multiplied by the longitudinal dimensions to give the shortening movement. However, the bridge deck may not have uniform shrinkage throughout the cross-section. For example, the top slab and bottom slab of an I-shaped girder or a box girder may shrink by different amounts. This gives rise to non-uniform shrinkage that, apart from causing shortening movement, also induces curling of the deck.

The shrinkage strain of concrete may be assessed based on the formulations in different design codes. In this study, the real bridge chosen as a numerical example is located in China and was designed according to Chinese Standard JTG D62-2004, reference is therefore made to this design standard. The provisions in JTG D62-2004 with respect to shrinkage are similar to those in CEB-FIP 
Model Code 1990, with modifications to suit the materials characteristics in China. As stipulated in JTG D62-2004, the shrinkage strain $\varepsilon_{c s}\left(t, t_{s}\right)$ of concrete at age $t$ (days) is evaluated as (Eq. (1)):

$$
\varepsilon_{c s}\left(t, t_{s}\right)=\varepsilon_{c s o} \beta_{s}\left(t-t_{s}\right)
$$

where $t_{s}$ is the age of concrete (days) when shrinkage starts, $\varepsilon_{c s o}$ is the notional shrinkage coefficient as given by Eq. (2), and $\beta_{s}\left(t-t_{s}\right)$ is a time-dependent coefficient as given by Eq. (3). Theoretically, at infinitely long time, the value of $\beta_{s}\left(t-t_{s}\right)$ would approach unity. Hence, the notional shrinkage coefficient $\varepsilon_{c s o}$ is representative of the ultimate shrinkage.

$$
\begin{aligned}
& \varepsilon_{c s o}=\varepsilon_{s}\left(f_{c m}\right) \beta_{R H}, \\
& \beta_{s}\left(t-t_{s}\right)=\left[\frac{\left(t-t_{s}\right)}{0.035 h_{e}^{2}+\left(t-t_{s}\right)}\right]^{0.5} .
\end{aligned}
$$

In the above equations, $\varepsilon_{s}\left(f_{c m}\right)$ is dependent on the 28-day mean cube compressive strength $f_{c m}$ of concrete, $\beta_{R H}$ is a coefficient dependent on the relative humidity, and $h_{e}$ is the characteristic thickness $(\mathrm{mm})$ of the structural component (same as the effective thickness defined above). Readers are referred to JTG D62-2004 for the valuation of $\varepsilon_{s}\left(f_{c m}\right)$ and $\beta_{R H}$. As can be seen from the above formulation, for a given concrete grade and for a given environmental relative humidity, the notional shrinkage coefficient and hence the ultimate shrinkage strain of concrete are constant, and are not affected by the characteristic thickness (which affects only the time-dependent coefficient $\left.\beta_{s}\left(t-t_{s}\right)\right)$ of the structural component. Never-

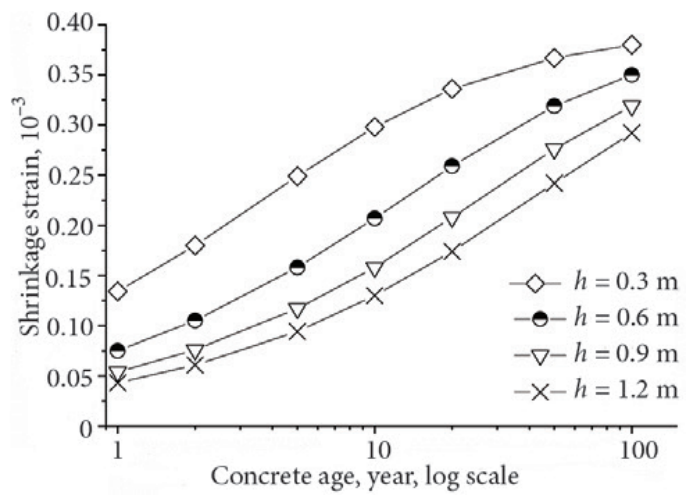

Figure 1. Variations of shrinkage strain with concrete age theless, the characteristic thickness of the component is an important parameter in determining the rate of drying shrinkage of concrete. Therefore, the shrinkage behaviour of structural members is largely dependent on the member geometry and dimensions.

To illustrate the above, consider long concrete panels of unit width subject to one-dimensional drying with moisture movement allowed only in the out of plane direction. The thickness of panel $h$ is varied among $0.3 \mathrm{~m}, 0.6 \mathrm{~m}$, $0.9 \mathrm{~m}$ and $1.2 \mathrm{~m}$. Assume the panels are cast of grade C55 ordinary Portland cement concrete, the relative humidity is $65 \%$ and the concrete starts to shrink from the fifth day after casting. The longitudinal shrinkage strains of the concrete panels are evaluated based on the relevant provisions in JTG D62-2004. The variations of shrinkage strain and concrete age so obtained are presented in Figure 1.

As can be seen from the curves in Figure 1, the rate of shrinkage is higher for a panel with smaller thickness, and vice versa. Furthermore, as reflected from the formulations stipulated in JTG D62-2004, the shrinkage strains of the concrete panels will converge to a certain ultimate value when the age of concrete approaches a very long period of time. The ratios of shrinkage strain of $0.3 \mathrm{~m}$ thick panel to those of other panel thicknesses at different ages are listed in Table 1. It is noted that the ratio is higher when the difference of panel thickness is larger, and when the concrete is at relatively early age. In any case, the ratio decreases with increasing age of concrete. Consider an Ishaped girder or a box girder, if the difference in thickness of the top slab and the bottom slab is large, correspondingly there would be large difference in shrinkage strains between the two slabs, and such differential shrinkage will eventually diminish.

\section{Equivalent transformation of non-uniform shrinkage}

\subsection{New simulation technique of non-uniform shrinkage}

The proposed simulation technique of non-uniform shrinkage is introduced in this section. Consider a section of box girder as shown in Figure 2, denote the thickness of top slab by $h_{t}$ and the thickness of bottom slab by $h_{b}$. For simplicity, suppose the top and bottom slabs are exposed to the same environmental conditions and are cast of the same concrete at the same time. If the thickness of the bottom slab is greater than that of top slab, i.e., $h_{b}>h_{t}$, a

\begin{tabular}{|c|c|c|c|c|c|c|c|c|c|}
\hline \multirow{2}{*}{$\begin{array}{l}\text { Thin panel, m } \\
\text { /Thick panel, m }\end{array}$} & \multicolumn{9}{|c|}{ Age, year } \\
\hline & 1 & 2 & 5 & 10 & 20 & 30 & 50 & 70 & 100 \\
\hline $0.3 / 0.6$ & 1.79 & 1.72 & 1.58 & 1.44 & 1.30 & 1.22 & 1.15 & 1.11 & 1.08 \\
\hline $0.3 / 0.9$ & 2.50 & 2.38 & 2.13 & 1.88 & 1.62 & 1.48 & 1.33 & 1.25 & 1.19 \\
\hline $0.3 / 1.2$ & 3.13 & 2.98 & 2.64 & 2.29 & 1.92 & 1.73 & 1.51 & 1.40 & 1.30 \\
\hline
\end{tabular}
larger shrinkage strain would be developed in the top slab

Table 1. The ratio of shrinkage strains of different thickness of concrete panels at different age 
at certain concrete age. Denote the shrinkage strain of top slab by $\varepsilon_{t}$ and the shrinkage strain of bottom slab by $\varepsilon_{b}$. It is known that the magnitude of $\varepsilon_{t}$ is greater than $\varepsilon_{b}$. This non-uniform shrinkage would induce shortening as well as a sagging curvature in the box girder. Due to the restraining effect of the fibres in the cross-section, it can be assumed that plane sections remain plane in the deformed girder. Figure 3 depicts the outline of the box girder along the longitudinal axis. The undeformed outline is represented in solid lines, whereas the deformed outline due to shrinkage is represented in dotted lines.

In analysing the time-dependent structural behaviour of the bridge using FE computer program, usually, the analysts may directly assign the axial shortening of beam elements. However, the curvature due to non-uniform shrinkage is not allowed for, and hence a specialised simulation technique becomes necessary. Denote $\Delta \varepsilon$ as the difference between $\varepsilon_{t}$ and $\varepsilon_{b}$, and $h$ as the structural depth of the box girder $(\mathrm{m})$. If the shrinkage of the webs and flanges is compatible such that the web sections do not restrain the shrinkage deformation of the slabs, the curvature $\varphi(1 / \mathrm{m})$ induced by the non-uniform shrinkage is mathematically given by Eq. (4):

$$
\varphi=\frac{\varepsilon_{t}-\varepsilon_{b}}{h}=\frac{\Delta \varepsilon}{h} .
$$

The curvature may be regarded as equivalent to the rotational deformation produced by a fictitious bending moment $M$ which is applied to a simply supported beam, as shown in Figure 4. Denote the flexural rigidity of the beam by $E I\left(\mathrm{kN} / \mathrm{m}^{2}\right), M$ is given by Eq. (5):

$$
M=E I \varphi=E I \frac{\Delta \varepsilon}{h} .
$$

The fictitious bending moment is prescribed through an equivalent temperature gradient across the section, as depicted in Figure 5. In doing so, the shrinkage strains of the top and bottom slabs are converted to equivalent thermal strains. Since shrinkage produces shortening movement, it is represented by thermal contraction, and hence temperature drop should be prescribed to the top and bottom slabs. By the assumption of the plane sections remain plane, the temperature gradient may be regarded as uniform. Suppose $T_{1}\left({ }^{\circ} \mathrm{C}\right)$ and $T_{2}\left({ }^{\circ} \mathrm{C}\right)$ are the temperature drop prescribed to the top slab and the bottom slab, respectively. They are related to the shrinkage strains by the coefficient of equivalent thermal expansion $\alpha\left(1 /{ }^{\circ} \mathrm{C}\right)$, as given in the below Eq. (6):

$$
T_{1}=\frac{\varepsilon_{t}}{\alpha}, T_{2}=\frac{\varepsilon_{b}}{\alpha} .
$$

Further, denote $\Delta T$ as the temperature difference $\left(\Delta T=T_{1}-T_{2}\right.$; in this context, $\left.\Delta T<0\right)$. From the above, $\Delta T$ is related to the difference in shrinkage strain of the top and bottom slabs. The equivalent temperature gradient is given by Eq. (7):

$$
\frac{\Delta T}{h}=\left(\frac{\varepsilon_{t}}{\alpha}-\frac{\varepsilon_{b}}{\alpha}\right) \frac{1}{h}=\frac{\Delta \varepsilon}{\alpha h} .
$$

Therefore, the flexural deformation of box girder caused by non-uniform shrinkage can be converted to the flexural deformation caused by an equivalent temperature gradient. This transformation technique can be utilised for the deformational analysis of box girders.

\subsection{Assessment of curvature}

The effects of non-uniform shrinkage on the curvature development in box girder sections are analysed. Dimensions of the cross-sections are shown in Figure 6 and are summarised as follows. The structural depth is $3.0 \mathrm{~m}$, the width and thickness of top slab are respectively $8.0 \mathrm{~m}$ and

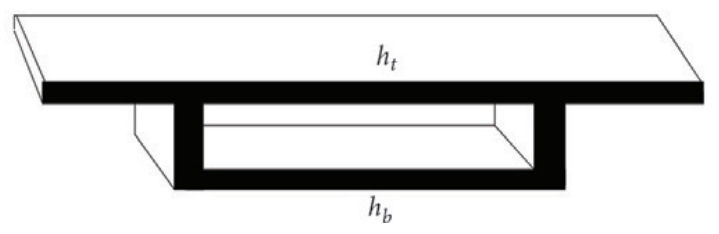

Figure 2. Box girder section with different thickness of the top and bottom slabs

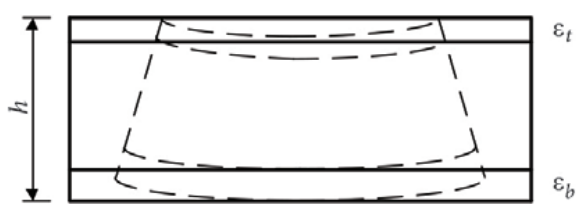

Figure 3. Outline of box girder section before and after shrinkage deformation

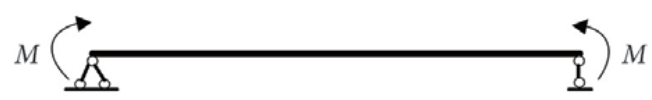

Figure 4. Fictitious bending moment applied to the simply-supported beam

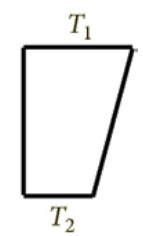

Figure 5. Equivalent temperature gradient

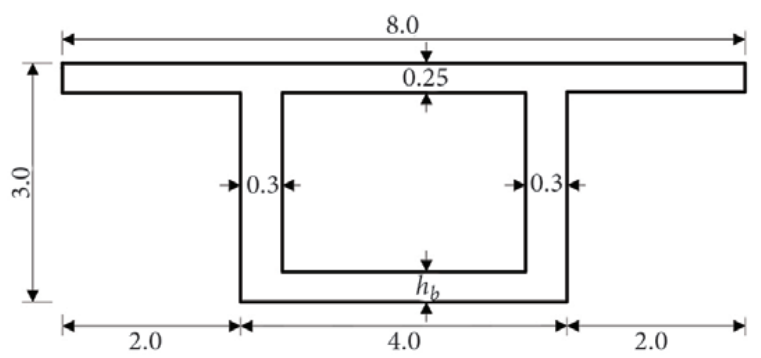

Figure 6. Cross-section of box girder with variable thickness of bottom slab (dimensions in $\mathrm{m}$ ) 
$0.25 \mathrm{~m}$, the thickness of web is $0.3 \mathrm{~m}$, the width of bottom slab is $4.0 \mathrm{~m}$, and the thickness of bottom slabs is varied among $0.3 \mathrm{~m}, 0.6 \mathrm{~m}, 0.9 \mathrm{~m}$ and $1.2 \mathrm{~m}$. Assume the concrete starts to shrink from the fifth day after casting. Due to the larger thickness of the bottom slab than the top slab, as discussed in the above, the top slab would exhibit a higher rate of drying shrinkage and sagging curvature will be induced in the box girder. The variations of curvature with the concrete age are plotted in Figure 7, and the numerical values of curvatures for the girder sections with varying thickness of bottom slab at different concrete age are tabulated in Table 2.

From Figure 7, it is observed that the curvatures of box girders first increase up to the maximum value, and then decrease gradually. The increase in curvature due to non-uniform shrinkage has been explained in the foregoing, and it is accompanied by an increase in downward deflection of the box girder. It should be noted that with the increase of concrete age, the rate of drying shrinkage eventually decreases. The reduction in the rate of drying shrinkage is also reflected in Figure 1. Initially, the top slab shrinks more rapidly. After a certain period of time, its rate of shrinkage will reduce to become smaller than that of the bottom slab. In other words, initially, the difference in shrinkage strains of the top and bottom slabs increases from zero to the maximum value. Subsequently as the rate of shrinkage of the bottom slab exceeds that of the top slab, the difference in shrinkage strains reduces, and this causes the curvature and the magnitude of downward deflection to decrease. The time to attain the maximum curvature is dependent on the slab thickness. As can be seen in Figure 7, the time is shorter when the difference in slab thickness is less, and is longer when the bottom slab is much thicker than the top slab.

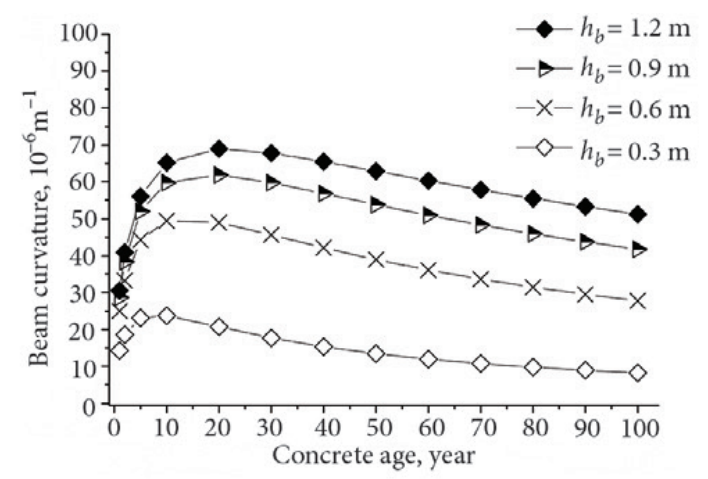

Figure 7. Time variations of curvature of girder sections
Theoretically, both the top and bottom slabs would eventually reach the same ultimate shrinkage strain, such that the curvature induced by non-uniform shrinkage would vanish. However, since concrete shrinkage is a long-term process, the curvature and deflection induced by the non-uniform shrinkage would reduce only very slowly after attaining their maxima and would exist mostly during the service life of the bridge structure. Besides, given the variable environmental condition, due allowance of the non-uniform shrinkage effect has to be made in assessing the long-term deformational behaviour of rigid frame bridges.

\subsection{Analysis procedure}

The proposed equivalent transformation technique is simple to apply in the bridge design process. For the general case of bridge configurations, the cross-section of box girder may be non-uniform, where the depth of girder and the thickness of slabs may be changing along the longitudinal direction. Due to the variable geometry of bridge girders, the shrinkage strains at different cross-sections and different locations of the girder section can be varying. Therefore, the effects of non-uniform shrinkage on the deformational behaviour can be complicated, and the FEM is usually required to perform structural analyses. The procedures for implementing the transformation technique in the analysis are presented in the flowchart in Figure 8.

As the equivalent temperature gradient is deterministic from the shrinkage strain, the solution process of FE analysis does not require performing iterations. The deformation response due to non-uniform shrinkage effect as obtained from the FE analysis is to be superposed to the deformation induced by the applied loads and environmental loads. On the other hand, the time-dependent stresses of the bridge structure should be computed with due consideration of the interaction between shrinkage and creep effects (Bačinskas, Kaklauskas, Gribniak, Sung, \& Shih, 2012; Gribniak, Bačinskas, Kačianauskas, Kaklauskas, \& Torres, 2013). In this respect, the step-by-step time integration method of FE analysis can be adopted (Kwan \& Ng, 2009, 2015). The above analysis procedures can be applied using a wide range of general-purpose FE computer programs, including the ones normally used in performing practical structural design. This allows improving the accuracy of deformation assessment in the design phase of continuous rigid frame bridges.

Table 2. The curvature of girder sections with varying thickness of bottom slab $\left(\times 10^{-6} / \mathrm{m}\right)$

\begin{tabular}{|c|c|c|c|c|c|c|c|c|c|}
\hline \multirow{2}{*}{$\begin{array}{c}\text { Bottom slab } \\
\text { thickness, } m\end{array}$} & \multicolumn{9}{|c|}{ Age, year } \\
\cline { 2 - 12 }$y$ & 1 & 2 & 5 & 10 & 20 & 30 & 50 & 70 & 100 \\
\hline 0.3 & 14.3 & 18.6 & 23.2 & 23.8 & 20.7 & 17.7 & 13.4 & 12.0 & 10.8 \\
\hline 0.6 & 25.0 & 33.2 & 44.3 & 49.5 & 49.0 & 45.7 & 38.9 & 36.1 & 33.6 \\
\hline 0.9 & 28.7 & 38.3 & 52.0 & 59.8 & 61.9 & 59.7 & 53.8 & 51.0 & 48.4 \\
\hline 1.2 & 30.5 & 40.9 & 56.0 & 65.2 & 68.9 & 67.8 & 62.9 & 60.3 & 57.8 \\
\hline
\end{tabular}




\section{Application of equivalent transformation technique}

\subsection{Bridge selected for study}

Lijiawa Bridge is located in Yan'an City in Shaanxi Province of China. It forms part of the Huangling to Yan'an Expressway running from south to north of Shaanxi Province. The bridge superstructure is in the form of prestressed concrete continuous rigid frame. It has a total length of $570 \mathrm{~m}$ with span length arrangement of $(75+3 \times 140+75) \mathrm{m}$. Figure 9 illustrates the elevation layout of the bridge. The deck girder is a hunched prestressed single-cell box girder. The structural depth varies from $3.2 \mathrm{~m}$ at mid-span to $8.3 \mathrm{~m}$ at support position, and the variation of depth follows a parabolic curve with an exponential index of 1.8. The width and thickness of the top slab are $16.65 \mathrm{~m}$ and $0.32 \mathrm{~m}$, respectively. The width of the bottom slab is $8.65 \mathrm{~m}$, and the thickness of the bottom slab varies from $0.32 \mathrm{~m}$ at mid-span to $1.0 \mathrm{~m}$ at the edge of support, and the variation of thickness follows a parabolic curve with an exponential index of 1.8. Atop the bridge piers, the thickness of the bottom slab is increased to $1.3 \mathrm{~m}$.

The span length of $140 \mathrm{~m}$ of the three main spans is regarded as long-span in the practical range of continuous rigid frame concrete bridges. The support condition of the three main spans is fixed support. The bridge has the special feature of having tall bridge piers, which are of different heights to suit the topology of the mountainous site. The piers at opposite sides of the end spans are respectively $25 \mathrm{~m}$ and $45 \mathrm{~m}$ in height. The piers of the three main spans, labelled as $P 1, P 2, P 3$, and $P 4$ as shown in Figure 9, have heights of $60 \mathrm{~m}, 124 \mathrm{~m}, 100 \mathrm{~m}$ and $65 \mathrm{~m}$, respectively. The bridge deck is fixed-supported on the piers $P 1$ to $P 4$ and is simply supported on the two piers at both ends. The bridge piers are of rectangular hollow section. Among the piers, $P 1$ and $P 4$ are split piers of double rectangular hollow sections. Since the bridge has the structural form of a continuous rigid frame, the use of split piers can reduce the shear stiffness so as to provide a certain degree of flexibility to cater for length changes of the bridge deck, while maintain a high flexural stiffness to resist bending moments.

Construction of the main bridge structure was commenced in 2013 and completed in 2015. The bridge deck was constructed by balanced cantilever method. Stressing of the tendons was carried out during the progress of constructing the bridge deck, which was cast of grade

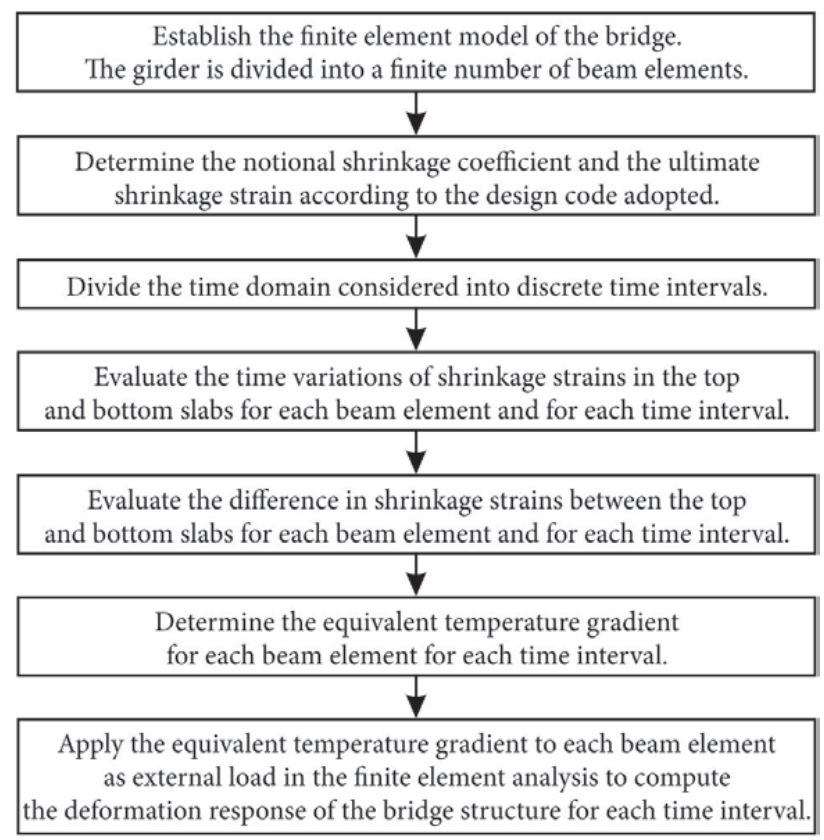

Figure 8. Procedures to analyse the non-uniform shrinkage effect
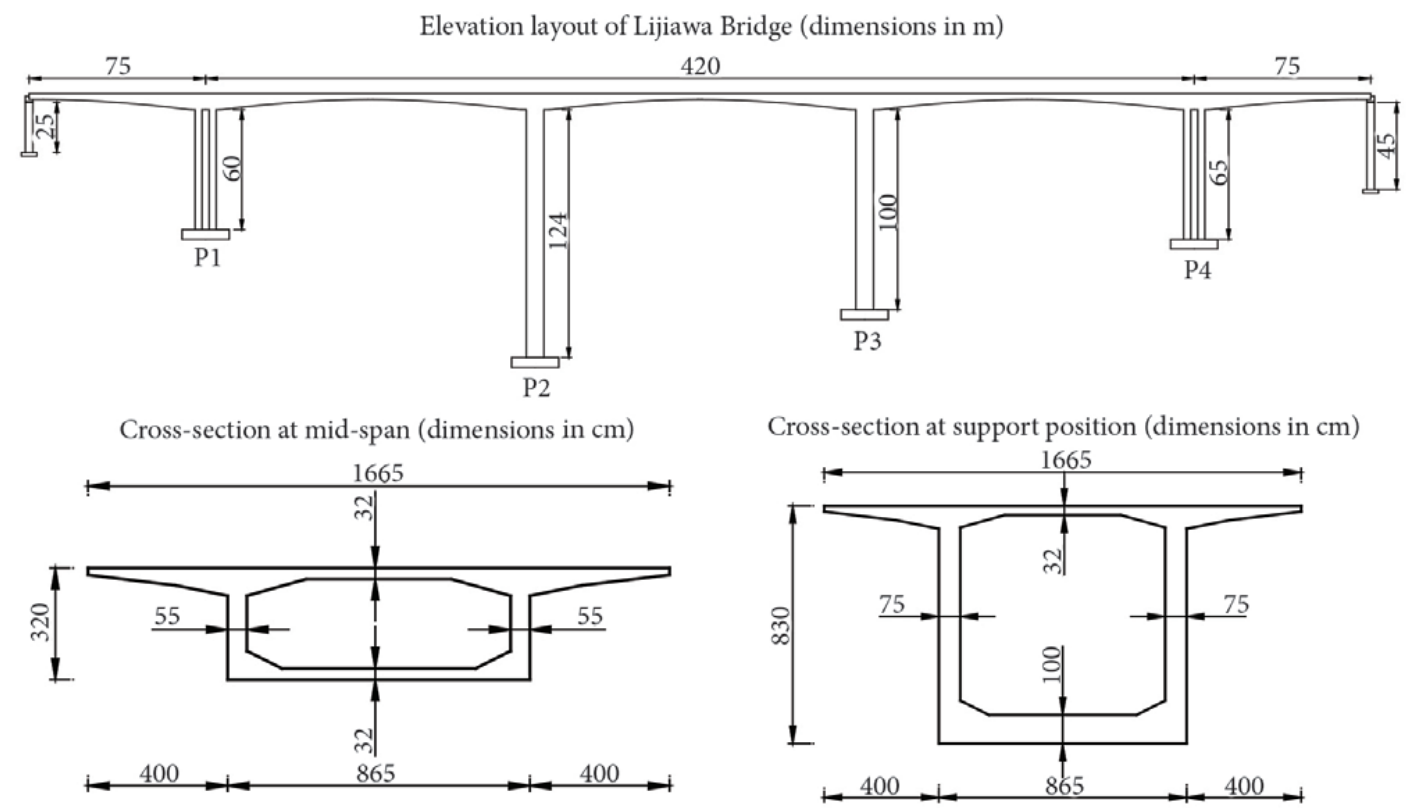

Figure 9. Elevation and cross-sections of Lijiawa Bridge 
C55 concrete. In the analysis, the construction sequence and the stage-by-stage changes of the partially completed bridge structure are not considered in the structural model. The reason is that the curvature arisen from the

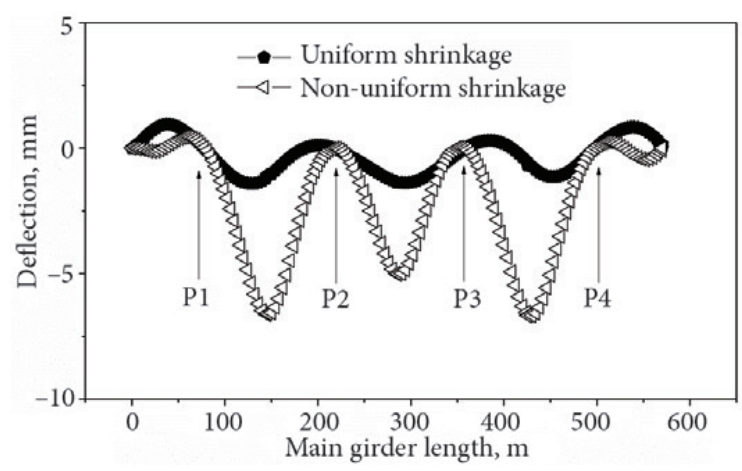

Figure 10. Computed deflections of main girder 1 year after completion of the deck

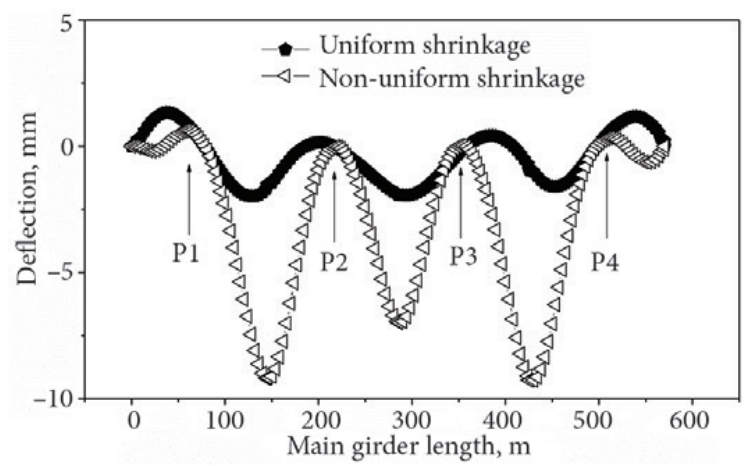

Figure 11. Computed deflections of main girder 2 years after completion of the deck

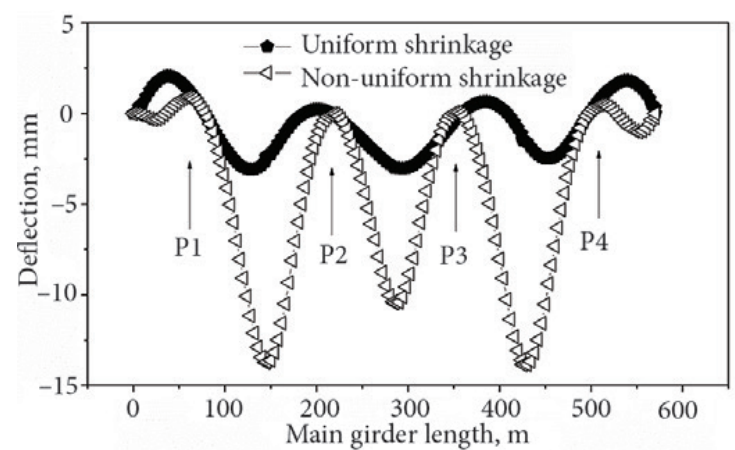

Figure 12. Computed deflections of main girder 5 years after completion of the deck

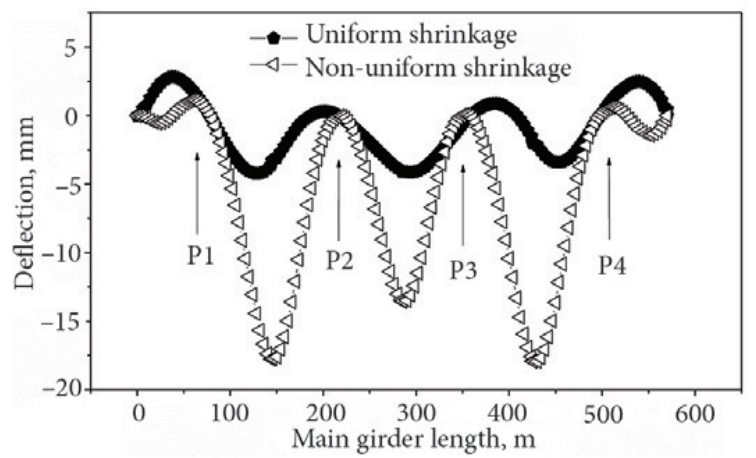

Figure 13. Computed deflections of main girder 10 years after completion of the deck construction sequencing could be corrected by appropriate pre-cambering before closure of the deck, and such is assumed herein to illustrate the effect of non-uniform shrinkage solely. However, in general circumstances, the influences of the construction sequence and the corresponding shrinkage that would occur during the construction stages should be duly included in the structural modelling.

\subsection{Analysis of non-uniform shrinkage effects}

The deflection of the main girder of Lijiawa Bridge due to non-uniform shrinkage effect is analysed. To demonstrate the feasibility of implementing the transformation technique with the use of general commercial FE software in engineering practice, a commonly used FE program Midas/Civil is employed for the analysis. In accordance with the bridge geometry, FE model of Lijiawa Bridge is established in Midas. The bridge girder is discretized into beam elements with a typical length of $1 \mathrm{~m}$, and the section properties are taken from the middle of the girder segments. Since the shrinkage occurs more rapidly at early age and its rate eventually diminishes, the division of time intervals is relatively fine initially and has gradually decreasing fineness. With the aid of a spreadsheet program, the shrinkage strains of the girder and equivalent temperature gradient for each beam element at different time intervals are determined.

The effects of selfweight, prestress force, deformation of substructure and other external loads are not included in the analysis to highlight the sole effect of non-uniform shrinkage on the deformational behaviour. Two scenarios of shrinkage are considered, namely 1 ) under uniform shrinkage of bridge girder; and 2) under non-uniform shrinkage of bridge girder. The computed vertical deflections of the main girder at 1 year, 2 years, 5 years, 10 years, 20 years and 100 years after completion of the deck structure construction for these two scenarios are shown in Figures 10-15.

It can be seen from Figures 10-15 that under the effect of uniform shrinkage, the end spans exhibit upward deflection, while other spans exhibit downward deflection, and these upward and downward deflections are very small comparatively. Under the effect of non-uniform

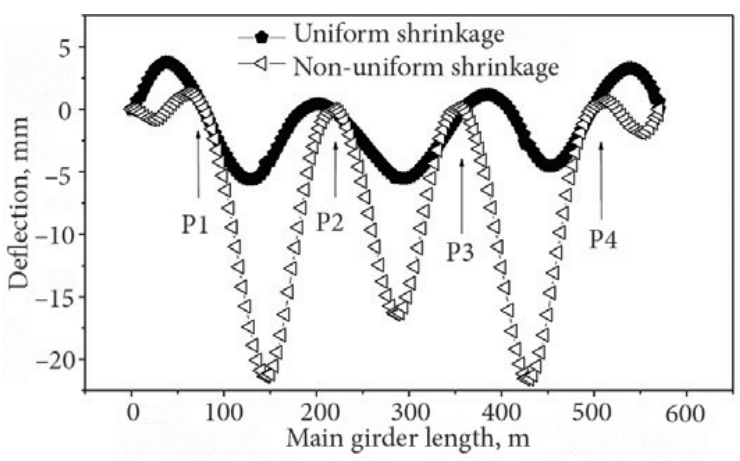

Figure 14. Computed deflections of main girder 20 years after completion of the deck 
shrinkage, only the regions near the continuous supports of end spans have small upward deflections, while other regions exhibit downward deflections. These downward deflections are much greater compared to those induced by uniform shrinkage. The maximum upward and downward deflections under the two scenarios are plotted in Figures 16-17.

Considering the upward deflections, under the effect of uniform shrinkage, the maximum upward deflection increases from $0.9 \mathrm{~mm}$ in the first year to $6.1 \mathrm{~mm}$ in the one hundredth year; whereas under the effect of nonuniform shrinkage, the maximum upward deflection increases from $0.4 \mathrm{~mm}$ in the first year to $1.0 \mathrm{~mm}$ in the one hundredth year. In the scenario of uniform shrinkage, the upward deflections continue to increase throughout the time period considered. In contrast, the upward deflection under the effect of non-uniform shrinkage first increases and subsequently decreases.

Considering the downward deflections, under the effect of uniform shrinkage, the maximum downward deflection increases from $1.4 \mathrm{~mm}$ in the first year to $9.2 \mathrm{~mm}$ in the one hundredth year; whereas under the effect of non-uniform shrinkage, the maximum downward deflection increases from $6.7 \mathrm{~mm}$ in the first year to $21.0 \mathrm{~mm}$ in the one hundredth year. In the scenario of uniform shrinkage, the downward deflections continue to increase throughout the time period considered. In contrast, the downward deflection under the effect of nonuniform shrinkage first increases to the maximum and then decreases. After the bridge deck being completed by 20 years, the maximum downward deflection caused by uniform shrinkage is $5.6 \mathrm{~mm}$, while the maximum downward deflection caused by non-uniform shrinkage is $21.6 \mathrm{~mm}$. The downward deflection under non-uniform shrinkage is substantially larger in magnitude (3.8 times) than that under uniform shrinkage. Therefore, neglecting the effect of non-uniform shrinkage would lead to serious errors in the deformation assessment of continuous rigid-frame bridges.

As can be seen from Figures 16-17, the maximum upward deflection increases slightly with time under uniform shrinkage, and is relatively stable under nonuniform shrinkage. The maximum downward deflection increases steadily with time under uniform shrinkage, and increases dramatically with time at the initial stage under non-uniform shrinkage. From the above, it is revealed that non-uniform shrinkage has a significant effect on the long-term deflection of bridge girder, and this also explains why the downward deflection of prestressed concrete continuous rigid frame bridge could continue to increase many years after completion of the deck, as reported in the relevant literature. Finally, it should be noted that the analysis results need to be combined with those under other load cases to assess the probable long-term deck deflections, and the time-variation of stresses need to be evaluated with the interaction between shrinkage and creep effects taken into account.

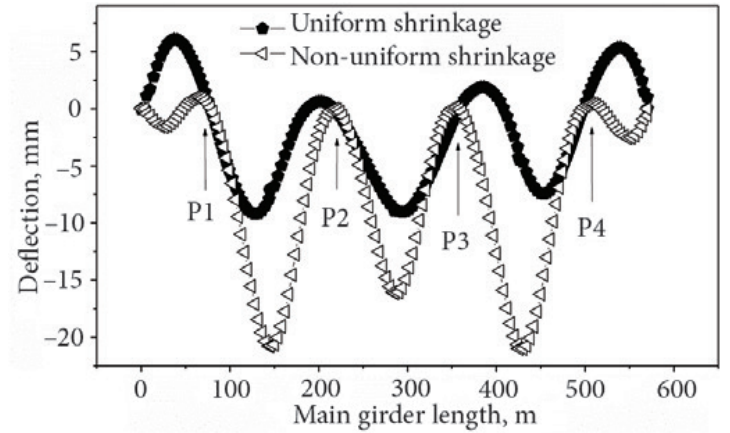

Figure 15. Computed deflections of main girder 100 years after completion of the deck

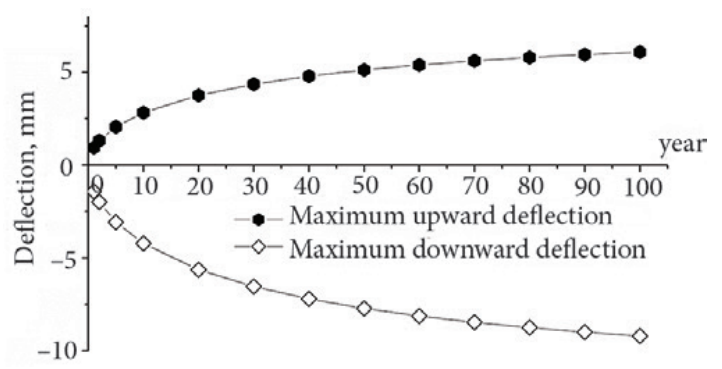

Figure 16. Variation of maximum deflections of the main girder with time under uniform shrinkage

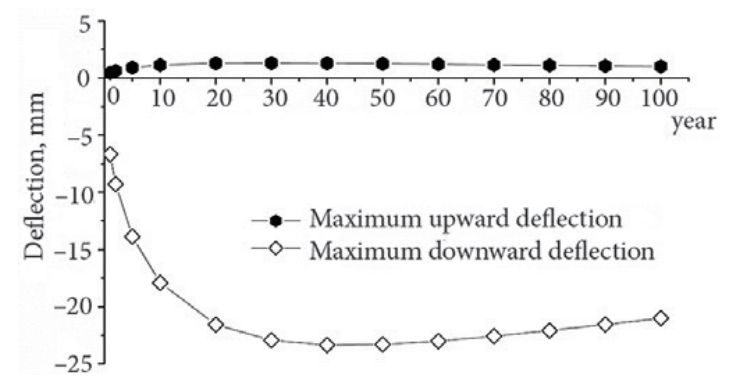

Figure 17. Variation of maximum deflections of the main girder with time under non-uniform shrinkage

\section{Conclusions}

Based on the above study on the analysis of non-uniform shrinkage in box girder sections for long-span continuous rigid frame concrete bridge, the following conclusions may be drawn:

1. A new simulation technique of non-uniform shrinkage has been developed. The non-uniform shrinkage effect of the box girder section is transformed to an equivalent temperature gradient and then applied as external load onto the beam elements in the finite element analysis.

2. Comparative analysis of vertical deflections of the main girder of a typical continuous rigid frame bridge, Lijiawa Bridge in China, under the scenarios of uniform shrinkage and non-uniform shrinkage has been performed. The numerical results have indicated that the maximum deflection of box girder under the action of non-uniform shrinkage is much greater than that under the action of uniform shrinkage. 
3. Taking the deflection results at 20 years after completion of bridge deck structure as an example, the maximum downward deflection of the main girder caused by uniform shrinkage is $5.6 \mathrm{~mm}$, whereas the maximum downward deflection caused by nonuniform shrinkage is $21.6 \mathrm{~mm}$, which is 3.8 times larger. Therefore, neglecting the effect of non-uniform shrinkage would lead to serious errors in the deformation assessment of continuous rigid-frame bridges.

4. This study has shown that non-uniform shrinkage of the box girder has a substantial effect on the long-term deflections of long-span continuous rigid frame bridge. The simulation of non-uniform shrinkage by the proposed equivalent transformation technique can significantly improve the deformation assessment in the design phase of bridges.

\section{Acknowledgments}

The first and last authors would like to gratefully acknowledge the financial support from Shanxi Provincial Transport Department of China (Grant No. 14 -16K), Ningbo Science and Technology Bureau of China (Grant No. 2015C110020), and Open Research Project of Key Laboratory of Transportation for Old Bridge Inspection and Strengthening (Beijing) in carrying out this research; the second author would like to express his gratitude for Marie Skłodowska-Curie Actions of the European Commission (Project No. 751461); the third author would like to express his gratitude for the financial support provided by the Research Council of Lithuania (Project No. MIP-093/2015).

\section{References}

Bažant, Z. P., \& Najjar, L. J. (1972). Nonlinear water diffusion in nonsaturated concrete. Matériaux et Construction, 5(1), 3-20. https://doi.org/10.1007/BF02479073

Bažant, Z. P., \& Baweja, S. (2000). Creep and shrinkage prediction model for analysis and design of concrete structures: Model B3. ACI Special Publications, 194, 1-84.

Bažant, Z. P., Yu, Q., Kim, K. T., Hubler, M. H., Šmilauer, V., Vráblík, L., Lepš, M., \& Kř́istek, V. (2011). Excessive multidecade deflections of prestressed concrete bridges: how to avoid them and how to exploit their monitoring to improve creep prediction model. Fib Symposium PRAGUE 2011: Concrete Engineering for Excellence and Efficiency. Czech Concrete Society.

Bažant, Z. P., Hubler, M. H., \& Yu, Q. (2011). Pervasiveness of excessive segmental bridge deflections: wake-up call for creep. ACI Structural Journal, 108(6), 766.

Bažant, Z. P., Yu, Q., \& Li, G. H. (2012a). Excessive long-time deflections of prestressed box girders. I: Record-span bridge in Palau and other paradigms. Journal of structural engineering, 138(6), 676-686. https://doi.org/10.1061/(ASCE)ST.1943-541X.0000487

Bažant, Z. P., Yu, Q., \& Li, G. H. (2012b). Excessive long-time deflections of prestressed box girders. II: Numerical analysis and lessons learned. Journal of Structural Engineering, 138(6), 687696. https://doi.org/10.1061/(ASCE)ST.1943-541X.0000375
Bačinskas, D., Kaklauskas, G., Gribniak, V., Sung, W. P., \& Shih, M. H. (2012). Layer model for long-term deflection analysis of cracked reinforced concrete bending members. Mechanics of Time-Dependent Materials, 16(2), 117-127.

https://doi.org/10.1007/s11043-011-9138-9

British Standards Institution. (1990). Steel, Concrete and Composite Bridges - Part 4: Code of Practice for Design of Concrete Bridges, BS 5400: Part 4: 1990. British Standards Institution, London, United Kingdom.

China Communications Construction Company Highway Consultants Co. Ltd. (2004). Code for Design of Highway Reinforced Concrete and Prestressed Concrete Bridges and Culverts, JTG D62-2004. China Communications Press, Beijing, China.

Comité Euro-International du Béton. (1993). CEB-FIP Model Code 1990: Model Code for Concrete Structures. Thomas Telford, London, United Kingdom.

https://doi.org/10.1680/ceb-fipmc1990.35430

Gribniak, V., Bačinskas, D., Kačianauskas, R., Kaklauskas, G., \& Torres, Ll. (2013). Long-term deflections of reinforced concrete elements: accuracy analysis of predictions by different methods. Mechanics of Time-Dependent Materials, 17(3), 297-313. https://doi.org/10.1007/s11043-012-9184-y

Huang, H. (2010). Large Span PC Box-Girder Bridge Long-Term Deflection Behaviour and Retrofitting Methods (PhD Thesis). Guangxi University, Guangxi, China.

Kř́stek, V., Bažant, Z. P., Zich, M., \& Kohoutková, A. (2005). Why is the initial trend of deflections of box girder bridges deceptive? $7^{\text {th }}$ International Conference CONCREEP, 7, 293-298.

Křístek, V., Bažant, Z. P., Zich, M., \& Kohoutková, A. (2006). Box girder bridge deflections. Concrete international, 28(01), $55-63$.

Křístek, V., Vráblík, L., Bažant, Z. P., Li, G. H., \& Yu, Q. (2009). Misprediction of long-time deflections of prestressed box girders: causes, remedies and tendon layout effect. $8^{\text {th }}$ International Conference on Creep, Shrinkage and Durability Mechanics of Concrete and Concrete Structures. Ise-Shima, Japan. https://doi.org/10.1201/9780203882955.ch169

Kwan, A. K. H., \& Ng, P. L. (2009). Shrinkage movement analysis of reinforced concrete floors constructed in stages. Computers and Concrete, 6(2), 167-185.

https://doi.org/10.12989/cac.2009.6.2.167

Kwan, A. K. H., \& Ng, P. L. (2015). Remnant creep based viscoelastic model for concrete creep analysis. Proceedings of the Institution of Civil Engineers-Structures and Buildings, 168(1), 3-14. https://doi.org/10.1680/stbu.13.00028

Navrátil, J., \& Zich, M. (2013). Long-term deflections of cantilever segmental bridges. Baltic Journal of Road \& Bridge Engineering, 8(3). http://doi.org/10.3846/bjrbe.2013.24

Robertson, I. N. (2005). Prediction of vertical deflections for a long-span prestressed concrete bridge structure. Engineering Structures, 27(12), 1820-1827.

https://doi.org/10.1016/j.engstruct.2005.05.013

Takács, P. F. (2002). Deformations in concrete cantilever bridges: observations and theoretical modelling (Doctoral Thesis). Department of Structural Engineering The Norwegian University of Science and Technology Trondheim, Norway.

Xiang, Z., Tan, J., Xu, H., \& Yan, N. (2011). Analysis of the nonuniform shrinkage result in long-term deformation for longspan box-girder bridge. Journal of Civil, Architectural and Environmental Engineering, S1, 84-87 (in Chinese). 
Xu, H., Tan, J., \& Li, L. (2010). Influence of cross section differential shrinkage on long-term deflection of long-span continuous rigid frame bridge. Highway, 4, 99-103 (in Chinese).

Xu, Z., Zhang, X., \& Xu, J. (2007). Analysis of parameters affecting the midspan deformation of continuous rigid frame bridge. Journal of Chongqing Jiaotong University (Natural Sciences), 26(4), 9-13 (in Chinese).

Zhang, Y., Meng, S., \& Liu, A. (2011). Influence of differential shrinkage on long-term deflection of long-span continuous rigid frame bridge. Journal of Xian Jiaotong University, 46(3), 379-384 (in Chinese).

Zich, M. (2002). Analysis of segmentally erected bridges with respect to differential shrinkage and shear lag ( $\mathrm{PhD}$ Thesis). Faculty of Civil Engineering, Brno University of Technology, Brno, Czech Republic (in Czech).

Zich, M., \& Navrátil, J. (2011). Analysis of segmentally erected bridges across Vltava River near Veprek with respect to differential shrinkage and creep, Beton - Technologie, Konstrukce, Sanace, 2/2011, 62-68 (in Czech). 